\title{
Uma nova governança no padrão de relacionamento público-privado da política industrial brasileira
}

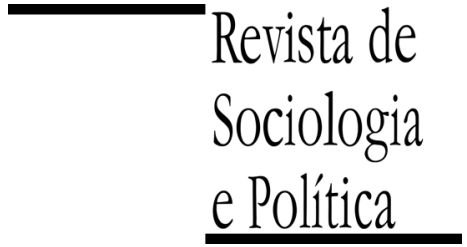

DOI 10.1590/1678-987315235506

\author{
Jackson De Toni
}

\begin{abstract}
Resumo
O objetivo central do artigo é a identificação de variáveis capazes de explicar um padrão virtuoso de relacionamento público-privado na produção de políticas públicas relacionadas à política industrial durante o primeiro governo Lula. O argumento central é que o Conselho Nacional de Desenvolvimento Industrial (CNDI), vinculado ao Ministério do Desenvolvimento, Indústria e Comércio Exterior (MDIC), atuou como arena público-privada de política industrial e legitimou-se como o lócus da agenda de política pública. Essa situação resultou da combinação de dois processos políticos distintos: (i) a influência das ideias neodesenvolvimentistas, em especial aquelas da nova política industrial e (ii) a ação de empreendedores políticos. A pesquisa baseou-se no estudo da dinâmica de funcionamento do CNDI, vinculado ao MDIC. Os dados foram obtidos pela análise das atas do colegiado, análise documental e entrevistas com os atores envolvidos. Os relacionamentos estabelecidos e a formação da agenda de política no conselho contribuiu para a definição da política industrial do período. O papel dos empreendedores políticos e do ideário neodesenvolvimentista contribuiu para a viabilidade dessa dinâmica. O artigo ajuda a entender a dinâmica dos fóruns tripartites de políticas públicas em contextos democráticos e as causas aparentes de seus êxitos e fracassos.
\end{abstract}

PALAVRAS-CHAVE: política industrial; arenas de políticas públicas; empreendedores políticos; neodesenvolvimentismo; governo Lula.

Recebido em 11 de Agosto de 2014. Aceito em 23 de Fevereiro de 2015.

\section{Introdução ${ }^{1}$}

\author{
1 Agradecemos aos \\ comentários e sugestões dos \\ pareceristas anônimos da \\ Revista de Sociologia e \\ Política.
}

$\mathrm{O}$ objetivo central da pesquisa é identificar variáveis capazes de explicar um padrão virtuoso de relacionamento público-privado na produção de políticas públicas relacionadas à política industrial durante o primeiro governo Lula. O argumento central é que o Conselho Nacional de Desenvolvimento Industrial (CNDI), vinculado ao Ministério do Desenvolvimento, Indústria e Comércio Exterior (MDIC), como arena público-privada de política industrial, legitimou-se como o lócus da agenda de política, a partir da combinação de dois processos políticos distintos: (ii) a influência das ideias neodesenvolvimentistas, em especial aquelas da nova política industrial e (ii) a ação de empreendedores políticos (De Toni 2013). Na formação fundacional, o CNDI foi composto por 12 ministros, pela presidência do Banco Nacional de Desenvolvimento Econômico e Social (BNDES), por dez líderes industriais e por dois representantes dos trabalhadores industriais. O estudo foca o período de criação do Conselho, em 2004 até o final do primeiro ano do segundo mandato de Lula, em 2007. Esses mecanismos atuaram simultaneamente naquela conjuntura, gerando relações institucionais intensas e uma criativa interação entre os diversos atores políticos participantes. O principal efeito dessas interações foi a capacidade gerada de coordenação intragovernamental. Isso, por sua vez, retroalimentou o processo de legitimação.

O mecanismo ideacional explicita a capacidade de as ideias criarem uma unidade de ação e uma percepção coletiva sobre os temas estratégicos: o que deve entrar e o que deve sair das pautas decisórias, isto é, o espaço de 
possibilidades de certos problemas e soluções. Por sua vez, a abordagem do empreendedorismo político estabelece que certos personagens podem reunir condições peculiares para mobilizar recursos e servir de "ponte" entre problemas, soluções e decisores. Eles podem criar janelas de oportunidade. A construção de relações produtivas entre os atores se relaciona aos ganhos de natureza qualitativa na relação entre gestores públicos e empresários privados no processo decisório em políticas públicas, em especial, relacionado ao acúmulo histórico das experiências das instâncias de cooperação público-privado, à formação de uma nova elite política na indústria e ao processo de aprendizagem coletiva. O marco teórico para analisar os processos sugeridos e identificar as relações de causalidade está baseado numa abordagem combinada entre o institucionalismo histórico (IH), que foca a influência das ideias (Sikkink 1991; Blyth 2001; Hall 2005; Schmidt 2008; Hay 2010), e o institucionalismo da escolha racional (IER), que foca o papel dos empreendedores políticos (Weingast \& Katznelson 2005; Kingdon 2011). As relações estabelecidas entre os atores são entendidas como generative relationships (Lane \& Maxfield 1996) nas arenas entendidas como "arenas de escolha" (Ostrom 1990; 2007). O conceito de coordenação governamental é aplicado a partir dos insights sugeridos pela "teoria da agenda" (Kingdon 2011). Veremos, na sequência, como esses conceitos se articulam e compõem um mosaico conceitual que permite analisar a dinâmica política do CNDI e deduzir como funcionam os mecanismos de cooperação.

\section{Referências teóricas e metodológicas}

Há 19 anos, Hall e Taylor (1996) diziam-se surpresos em como as diferentes escolas (neo)institucionalistas permaneciam fechadas, sugerindo um aumento de intercâmbios entre as duas abordagens. Nesse período, inúmeras tentativas de convergência teórica foram feitas. Como em todas as tentativas de integração teórica, o problema geralmente reside na busca de uma lógica de complementação que faça sentido explicativo. Parece que essa possibilidade se encontra mais facilmente quando uma das abordagens chega a uma situação limite para explicar um fenômeno qualquer, ou seja, a observação da realidade apresenta sistematicamente episódios ou características não previstos ou explicados pelo modelo teórico. Weingast e Katznelson (2005), por exemplo, sugerem que as preferências sejam de fato imputadas aos atores a partir de um modelo ou estrutura teórica, mas sugerem também que são formadas por processos históricos e induzidas por circunstâncias de interação estratégica com outros atores. Ambas as escolas, racional e histórica, compartilham a visão de que as instituições são mecanismos que podem resolver ou agravar os problemas de coordenação e cooperação, com múltiplas dimensões com essa finalidade. Eles reconhecem que, na abordagem histórica, o comportamento dos atores, que muda em cada contexto, com múltiplas causas imprevisíveis e indeterminadas, é muito mais complexo que a aplicação da "teoria dos jogos" pela IER, ainda que os modelos sejam elegantes e sofisticados. Foi nesse sentido que trabalhos marcantes de autores como Bendix, Moore, Hall, Immergut, Skocpol, Steinmo, Thelen e Tilly, ao abordarem processos relacionados à consolidação do capitalismo ocidental, à urbanização, à fenômenos da economia política ou a transição do feudalismo, tenham empreendido uma análise que, a partir da compreensão profunda de casos singulares, pudesse identificar possíveis relações de causalidade e generalizações contextualizadas.

Na mesma direção, Thelen e Mahoney (2010) trabalham a estratégia de unir micro e macro fundamentações das preferências e das instituições, como se o foco racionalista e o histórico fossem duas faces de uma mesma moeda. Segundo eles, a grande maioria dos estudos que focalizam processos de dependência da trajetória em mudanças de longo curso e de caráter irreversível (por 
exemplo, a transição do feudalismo para o capitalismo) não explicam bem como é que os atores fazem suas escolhas e mudam suas condutas. Para eles, os atores são inspirados por convicções normativas profundas, estudadas na análise histórica, que não raro remonta ao processo de socialização familiar, cultural, escolar etc. Gostos e hábitos são internalizados dentro do convívio prolongado em um grupo socioeconômico. As posições de classe ofereceriam oportunidades e incentivos semelhantes. Mahoney (2010), por exemplo, trabalha com a ideia de complementação conceitual: os modelos inspirados no racionalismo ou no historicismo puro não capturam a complexidade da realidade, a modelagem de eventos críticos e a análise da trajetória em IH pode ser, nesse sentido, micro-fundamentada por estudos de IER, como se fossem camadas conceituais, apenas se distinguindo pela escala, profundidade e estratégias cognitivas, e não pela sua natureza ou conteúdo:

"[...] scholars affiliated with RCI stand to benefit from the concern of HI with empirically justifying assumptions about actor goals and assessments. Moreover, HI can contribute to RCI by identifying those specific periods when actor choices are especially consequential and thus need to be carefully modeled [...]. Scholars in the field of HI can benefit from the concern of RCI with rigorously modeling the mechanisms through which actor make choices during key historical periods [...]" (Mahoney 2010, p.330; sem grifos no original).

No caso da política industrial, desde 2003, o ideário desenvolvimentista foi a base de uma nova identidade que unificou atores nem sempre alinhados (a coalizão liderada pelo Partido dos Trabalhadores e parte significativa da elite industrial de capital nacional). As ideias sobre um novo modelo de desenvolvimento, baseado nas premissas de recuperação do papel do Estado como ator ativo foram veiculadas por atores concretos a partir de mudanças na conjuntura externa e interna (processo de desindustrialização e a ameaça dos concorrentes asiáticos, desde os anos 1990), por interesses materiais imediatos (bloquear ou minimizar os danos do processo de desnacionalização) e pela estratégia política do governo federal (geração de empregos industriais como parte de uma estratégia redistributiva). Esses atores foram portadores de novas articulações e coalizões políticas. No caso da política industrial lulista, há um duplo resgate. Por um lado, a trajetória partidária, sindical e social dos novos dirigentes os direciona para soluções mais concertadas, coletivas e participativas, por outro, há também uma expectativa de retomada das políticas ativas em relação à indústria, por oposição ao fracasso das políticas industriais (ou a ausência intencional das mesmas), associadas à coalizão política eleitoralmente derrotada (Governo FHC, PSDB), em especial ao processo de privatização/desnacionalização e à apreciação cambial gerada pelo Plano Real, de 1994 (contra a qual se insurgiram parte do capital industrial local).

Em trabalho mais recente, Hall (2010), toma como base os princípios da abordagem racionalista e tenta sofisticar o modelo utilizando o instrumental analítico histórico. Como Weingast (2005), Hall credita, à capacidade mobilizadora dos empreendedores, parte da responsabilidade para superar os dilemas da ação coletiva e esclarecer os custos de oportunidade que serão maiores ou menores conforme a intensidade da dependência do passado (trajetória). Mas o ponto que queremos ressaltar é que os empreendedores políticos não atuam num tempo histórico estático ou num campo neutro de relações de poder. Eles mesmos são condicionados por trajetórias distintas, por custos de oportunidade e riscos que mudam a cada conjuntura de acordo com as ideias hegemônicas ou dominantes e as janelas de oportunidade.

Os mecanismos explicativos sugeridos - empreendedorismo e a dinâmica ideacional - perdem sentido se analisados dentro de seus respectivos marcos conceituais isoladamente. O empreendedorismo, no caso do CNDI, pode ser observado tanto a partir de agentes ou atores individuais (o Ministro Furlan ou o 
${ }^{2}$ Sobre o papel desempenhado pelos processos de mimetização (mimicking) de modelos de sucesso, sobretudo de receituários prescritivos de organismos internacionais e a construção discursiva de um "modelo de sucesso", ver o interessante trabalho de Tapia e Gomes (2008). empresário Gerdau, por exemplo) como atores institucionais (os ministérios e agências públicas e privadas). O que importa é identificar o papel que eles desempenharam num contexto histórico específico, fora do qual não teriam sentido e intensidade para transformar a natureza das relações público-privadas naquela arena. Nesse contexto, por sua vez, a dinâmica ideacional - que se desdobra em várias dimensões normativas sobre a ideia de desenvolvimento econômico e industrial e a relação estado/sociedade - vai estabelecer um campo de ação para os empreendedores, com limites e oportunidades, possibilidades e riscos. Vamos aprofundar essas reflexões nas próximas seções.

Na trajetória epistêmica do institucionalismo histórico, o papel das novas ideias e dos roteiros cognitivos foi sempre fundamental para explicar os mecanismos de formulação de políticas públicas. No estudo clássico de Hall sobre a disseminação de ideias keynesianas em diversos países no período entre guerras, fica evidente a importância dessa variável na definição de preferências, comportamentos e instituições (Hall 1989). Nesse estudo Hall vai identificar três grandes mecanismos causais que podem explicar as diferenças de difusão ideacional em cada contexto nacional: uma centrada na economia, outra na ação do Estado e, finalmente, uma terceira centrada em coalizões. Hall sugere alguns fatores para entender o impacto de novas ideias sobre as políticas: a orientação do partido no governo, a estrutura do Estado e relações com a sociedade, o tipo de discurso político e o impacto de eventos exógenos. Em relação ao Estado, Hall sinaliza que não é condição suficiente a existência de empreendedores políticos se as estruturas estatais não são ocupadas por gestores públicos com autoridade e capacidade técnica para implementar mudanças no programa, no ideário. Segundo o autor, (i) a permeabilidade dos funcionários ao novo; (ii) a maior ou menor concentração de poder na área em que as novas ideias serão recepcionadas e (iii) o poder do órgão ou agência envolvida (no caso específico, os bancos centrais nacionais), seriam fatores essenciais. O impacto das novas ideias relacionado à natureza do discurso político dependeria de quanto essas ideias dialogam com a memória coletiva, com experiências passadas, em diferentes semânticas políticas ou mimetizando modelos de sucesso ou percebidos como tal ${ }^{2}$. A capacidade efetiva que novas ideias têm ou não de condicionar ou influenciar preferências, interesses e mudanças institucionais depende de quais arranjos (matrizes) institucionais prévias estavam operando e do curso prévio de ação dos atores sociais relevantes.

Sikkink (1991), na trilha sugerida por Hall, aplica esse mesmo raciocínio na tentativa de entendimento do porquê de as ideias desenvolvimentistas, apesar de terem sido divulgadas quase que simultaneamente na Argentina e no Brasil nos anos 1950, só tiveram recepção mais efetiva neste último. Ela constrói os nexos causais dessa diferença em múltiplos eventos: no Brasil havia tomadores de decisão (pivotal decision makers, nos termos de Weingast 2005), na Argentina, não; no Brasil havia mais state capacity, uma burocracia mais adaptada (o caso do BNDES foi emblemático); a ideologia e as instituições pré-existentes recepcionaram as ideias desenvolvimentistas (uma espécie de harmonização com o zeitgeist ou o esprit de l'époque) ao contrário da Argentina. Sikkink (1991) reforça Hall (1989): novas ideias não entram num "vácuo ideológico", elas são inseridas num espaço político já ocupado por ideologias anteriores e são veiculadas concretamente por atores historicamente determinados, em contextos específicos. Blyth (2001) alerta que em certos contextos as ideias ganham autonomia diante de seus autores, podendo ser disseminadas em processos que não são lineares, mas lentos e custosos. Blyth (idem) examina o papel das ideias na dinâmica institucional a partir de três perspectivas distintas, embora complementares: ideias como desenho institucional (institutional blueprint) em períodos de crise, como armas (weapons) em períodos de disputas distributivas e como "cadeados cognitivos" (cognitive locks). 
${ }^{3}$ PITCE: Política Industrial, Tecnológica e de Comércio Exterior (2004). PDP: Política de Desenvolvimento Produtivo (2008).

${ }^{4}$ D'Araujo $(2007 ; 2009)$ afirma que $45 \%$ dos ocupantes de cargos comissionados (de livre nomeação dos gestores políticos) de alto escalão do governo federal lulista tiveram origem em sindicatos de trabalhadores cuja cultura política é geralmente participativa.
A última categoria ajuda a entender a trajetória do CNDI e a conformação de suas agendas de debates. Ele foi uma arena de alto nível hierárquico, fortemente centralizada e pouco vinculada às instâncias "de base" e com funções representativas não claramente definidas (não havia mandatos ou delegações), pois a indicação de seus participantes era individual e não estava ligada a suas respectivas entidades empresariais de origem. As ideias sobre política industrial condicionavam a pauta de ação dos empreendedores políticos, por sua vez, os acordos possíveis dentro do CNDI configuravam uma situação de auto-coordenação governamental, condição sine qua non para sua efetividade. As diversas políticas industriais do período, a PITCE, em 2004, e a PDP, em 2008, ${ }^{3}$ ofereceram um тепи de temas e oportunidades disponíveis que de certa forma condicionou o roteiro do processo decisório de governo, de empresários industriais e de trabalhadores, em menor escala. Para Schmidt (2008), as ideias são os elementos-chave na análise dos contextos mais amplos onde ocorrem os eventos políticos. As ideias não só se relacionam com as estruturas de poder, mas permitem a possibilidade de agência dos atores, quando comandam e servem como "guia" para a escolha, para a ação e para o comportamento individual ou coletivo. A influência de novas ideias sugere que o Governo Lula inovou parcialmente a tradição política pré-existente (na esfera do governo federal), por força de seu projeto político ideológico que enfatizava mecanismos de participação, ampliação da democracia formal e o uso ativo do Estado para redistribuição de renda ${ }^{4}$. Essa renovação do ideário foi fortemente influenciada pelas condições contextuais e históricas, sobretudo a estabilidade econômica herdada do governo anterior, as condições externas favoráveis de crescimento econômico (apesar da crise internacional de 2008) e as condições políticas internas, de razoável governabilidade. Essas "novas ideias" relacionadas a um novo estilo de governo, com ênfase em procedimentos mais participativos e coletivos, acabaram também influenciando o campo de políticas de desenvolvimento econômico.

Conforme sugerem Boschi e Gaitán (2008, p.104):

"[...] o governo Lula se notabilizou pelas iniciativas de cooperação sistemática entre o setor público e privado: A cooperação entre as elites econômicas locais e os esforços coordenados de vários segmentos da burocracia são importantes no sentido de se definir estratégias de desenvolvimento. De fato, a cooperação entre os setores público e privado é o centro das iniciativas do governo Lula, desde o planejamento estratégico realizado no início de seu primeiro mandato até as políticas de Arranjos Produtivos Locais e as Parcerias Público-Privadas. Mais recentemente, além de uma série de conselhos de cunho consultivo, tem sido ativados um conjunto de fóruns voltados à discussão de prioridades públicas envolvendo diferentes segmentos da sociedade civil e do Estado" (sem grifos no original).

A literatura tem apontado para a retomada de um projeto desenvolvimentista com reativação do papel do Estado no uso ativo de instrumentos típicos da ação estatal (empresas estatais, concessão de subsídios ou definição de conteúdo local para discriminação de preços, por exemplo) no processo de desenvolvimento (Bresser-Pereira 2007; 2011), em bases diferenciadas do que ocorreu entre o fim da II Guerra Mundial e a década de 1970, quando se formou o parque industrial brasileiro. Essa nova hegemonia - não totalmente consolidada, dadas as potenciais contradições entre esse ideário e a manutenção da ortodoxia macroeconômica - é o legado direto da crise do modelo neoliberal na segunda metade dos anos 1990. Nesse caso a criação de "arenas" em política industrial representou um inovador processo de concepção e ideias vinculado a um ideário mais democrático sobre o funcionamento do governo e os objetivos do desenvolvimento. Lula combinou um modelo "centrado no Estado" com uma via "centrada em coalizões", na tipologia proposta por Hall. 


\section{II.1 A ação de empreendedores políticos nas arenas decisórias}

Originalmente o conceito de empreendedorismo esteve associado aos estudos já clássicos sobre a formação e a dinâmica do capitalismo, desde sua fase concorrencial e industrial inicial. O conceito já aparece no século XIX, em Say (1983), com a ideia do empresário empreendedor que assume riscos e que organiza o processo produtivo, reunindo trabalhadores e máquinas. O "empresário empreendedor" é imediatamente associado a um dos valores básicos do liberalismo, ou seja, à crença na individualidade, ou melhor, na capacidade individual e no relacionamento social competitivo entre indivíduos, como base do capitalismo moderno. Em Schumpeter (1982), há uma ressignificação da natureza do empreendedor, ao lhe atribuir uma capacidade de inovação, de mudança contínua, oposta à visão de equilíbrio dos primeiros liberais. O "empresário schumpeteriano" é por excelência o empresário empreendedor, equivalente ao "empresário inovador", disposto a correr riscos transformando crises em novas oportunidades. Surgido no campo da economia e da administração empresarial, o conceito de empreendedorismo, ou de empreendedor, foi absorvido pelos estudos comportamentalistas dos anos 1960 e depois foi incorporado aos estudos organizacionais e gerenciais sobre a administração de empresas (Costa, Barros \& Carvalho 2011). Originalmente, o conceito estava associado à capacidade de identificar oportunidades, relacionar-se em rede e possuir habilidades comportamentais de gestão e posicionamento pessoal em diferentes cenários e conjunturas. Nos estudos sobre a administração pública, por exemplo, a figura do empreendedor público adquiriu importância durante as reformas liberais dos anos 1980 e 1990, como a figura-chave para otimizar recursos em novas formas gerenciais e maximizar a produtividade e a eficácia no setor público (Osborne \& Gaebler 1992).

Ao contrário do empreendedor privado, a motivação do empreendedor político não é o lucro, na medida em que empreendedores políticos, salvas raras exceções, não são titulares dos ativos que comandam ou das inovações que provocam nas políticas públicas. Segundo a percepção mais associada à escola racionalista, os objetivos estariam ligados a uma multiplicidade de motivações intangíveis: sucesso político e status, progressão na carreira, controle de recursos críticos, reconhecimento público, prestígio pessoal, êxito de coalizões políticas etc. No decorrer da política industrial lulista, o surgimento de empreendedores políticos esteve associado à posição de liderança de classe no caso dos empresários, à liderança governamental no caso dos gestores públicos e na função de intermediação técnica no caso dos empreendedores políticos coletivos, com a Agência Brasileira de Desenvolvimento Industrial (ABDI).

A existência de empreendedores políticos é, sem dúvida, uma variávelchave para explicar o funcionamento das arenas políticas. Weingast (2005), por exemplo, sugere enriquecer as análises clássicas do institucionalismo da escolha racional usando princípios macroscópicos de análise como a estrutura de poder, o papel das ideias na mudança institucional e os eventos críticos na formação das preferências. Mas sua ênfase recai sobre o papel dos empreendedores políticos. Ele sugere que em cada evento crítico o pesquisador identifique um "decisor estratégico" ou "pivotal" (pivotal decision maker) que obedeça às seguintes condições: é aquele indivíduo (ou grupo) cujo abandono do status quo e migração para um novo posicionamento seja capaz de catalisar ou mover todos os demais para esse novo posicionamento, gerando uma ruptura com o estado de poder, as crenças e as legitimidades estabelecidas. Weingast (idem) aponta como variáveis centrais para explicar a motivação do "grupo pivotal" os seguintes fatores: $(i)$ capacidade de convencimento dos demais grupos e indivíduos, quanto maior o número de "convertidos" maiores as probabilidades de mudança; (ii) eventos externos ao controle do pivotal decision maker devem 
${ }^{5}$ Calculando probabilidades críticas de mudança, de permanência na situação atual e de riscos envolvidos, o autor aplica o modelo ao estudo da Revolução Americana, batizado por Weingast de "racionalidade do medo" (rationality of fear). confirmar, como evidências materiais, os indícios de benefícios futuros maiores que os custos da mudança, para os grupos ainda não convertidos; (iii) tudo depende, afinal, de "compromissos credíveis" (credible commitments) dos empreendedores políticos, que se relaciona também com sua reputação pregressa e sua posição de poder no grupo ${ }^{5}$.

Os empreendedores políticos também são fundamentais para a formação das agendas em políticas públicas, segundo Kingdon (2011). Kingdon reputa à ação do empreendedor a capacidade de juntar ou unificar a compreensão de um problema, com as condições políticas para resolvê-lo e a existência de instrumentos disponíveis de política pública para tanto. $\mathrm{O}$ empreendedor pode estar dentro ou fora do governo, numa instância formal ou informal; pode ser um gabinete ministerial ou um congressista, um acadêmico ou um lobista. Os empreendedores políticos teriam características específicas: capacidade de se fazerem ouvir, derivada da expertise, liderança ou autoridade; capacidade de estabelecer conexões políticas e negociar a alocação de recursos políticos entre os "jogadores", combinando experiência política (political savvy), com conhecimento técnico (technical expertise) e finalmente, persistência. Kingdon reputa esta última como a principal característica do empreendedor:

"Many potentially influential people might have expertise and political skill, but sheer tenacity pays off. Most of these people spend a great deal of time giving talks, writing position papers, sending letters to important people, drafting bills, testifying before congressional committees and executive branch commissions, and having lunch, all with the aim of pushing their ideas in whatever way an forum might further the cause [...] Entrepreneurs are ready to paddle, and their readiness combined with their sense for riding the wave and using the forces beyond their control contributes to success. (idem, p.181; sem grifos no original)

Para esse autor, haveria dois tipos de empreendedores: os que atuam publicamente e os "participantes invisíveis" que atuam na formulação técnica das alternativas, geralmente membros da burocracia pública ou de organizações de lobby privado. Acadêmicos e pesquisadores de think tanks também podem ser "invisíveis" no processo de formulação de alternativas, por meio de contatos com congressistas, consultorias privadas e uso da mídia. Para Kingdon (idem), o Presidente da República é o empreendedor político principal, entretanto a definição de alternativas técnicas, após a direção escolhida, foge-lhe do controle e está sob influência dos especialistas. Essa situação conduz a um contexto permanente de negociação entre os gestores eleitos e a burocracia permanente do Estado. O presidente é o ator mais forte da agenda, mas Kingdon é taxativo ao afirmar que ele está submetido à escolhas técnicas, não tendo poder absoluto de determinar a alternativa escolhida. Por isso, a burocracia pública também é decisiva, em especial os altos escalões gerenciais, assessores ministeriais e dirigentes públicos. Eles têm acesso privilegiado às informações, aos grupos de pressão e têm autoridade legal em muitos casos Os congressistas, de um modo geral, são empreendedores naturais, mais estáveis que o primeiro escalão dos governos e muitas vezes com maior capacidade de veto e barganha. O empreendedor político possui basicamente um comportamento oportunista, no sentido de que aproveita as "janelas" de oportunidade para advogar e defender uma proposta e liderar uma coalizão específica. Ele age também como um broker, segundo Kingdon (idem), negociando diferentes posicionamentos, combinando problemas, políticas e soluções (coupling shifts).

Essa caracterização do empreendedor político, como um intermediário dos fluxos de informação, também aparece na caracterização do empreendedor como uma "ponte" (hub), nos nós de uma ou mais redes de interesse, mobilizando recursos e novas formas organizacionais através da densidade de suas conexões (Burt 2004). Na análise da dinâmica do CNDI é fácil constatar que a ação dos empreendedores foi responsável pelos momentos de maior criati- 
${ }^{6} \mathrm{O}$ termo "relações fecundas" (generative relations) foi sugerida inicialmente por Abers e Keck (2008).

\footnotetext{
${ }^{7}$ A pesquisa empírica foi feita no âmbito do trabalho de doutoramento do autor no Instituto de Ciência Política (IPOL), da Universidade de Brasília (UnB), apresentada em 2013, sob o título "Novos arranjos institucionais na política industrial do governo Lula: a força das novas ideias e dos empreendedores políticos".
}

${ }^{8}$ Concordando com Schneider (2010), considera-se prudente diferenciar que, além do uso vidade propositiva daquela arena. Os empreendedores atuavam sobretudo para dar concretude à pauta da política industrial, que no seu conjunto, como teoricamente anunciado pelo governo, era grande, complexa e muito ambiciosa. O pragmatismo dos empreendedores, sobretudo do então Ministro do MDIC, Luiz Furlan, traduziu-se no agendamento, debate e encaminhamento dos temas críticos ou possíveis, dada a correlação de forças internas no conselho. Houve também um tipo de "empreendedorismo organizacional" ou "coletivo", protagonizado pela nova agência governamental criada, a Agência Brasileira de Desenvolvimento Industrial (ABDI, criada em 2004), que desempenhava a função de secretaria executiva do colegiado. A Agência garantia uma base técnica negociada com o setor privado, condição essencial para construir os pactos políticos no interior da arena.

Lane e Maxfield (1996) sugerem ações para ativar o potencial das "relações fecundas" entre as pessoas. A expressão "relações fecundas" significa a justaposição de diferentes interesses e experiências e pontos de vista, numa arena pública, como necessários e essenciais para a produção de inovações. O elemento que catalisa esse processo está além da interação de ideias e interesses. Ele resulta da constituição de relações concretas e objetivas que os atores desenvolvem entre si e as capacidades para usarem os recursos disponíveis de forma inédita. As relações informais entre participantes de arranjos colaborativos também é enfatizada por outros autores. Donahue e Zeckhauser (2006), por exemplo, sugerem que boa parte das relações virtuosas entre empresários e governo no complexo industrial-militar norte-americano derivam desse tipo de relações.

Elas se baseiam mais em afinidades culturais e sociais, por exemplo, uma trajetória ou origem social comum e códigos implícitos de conduta, do que nos contratos formais. As evidências de pesquisa apontam para o estabelecimento desse tipo de relação entre as partes envolvidas no $\mathrm{CNDI}^{7}$. Apesar das diferentes posições, inclusive dentro do governo, sobre o ritmo ou a profundidade das medidas a serem processadas, a densa interação entre os atores criou uma base comum sobre política industrial, alinhada com as novas ideias sobre desenvolvimento econômico. O modo como o conselho tratava os temas potencialmente conflituosos, como a política cambial, ajuda a entender o modus operandi daquela arena. Os atores, públicos e privados, sabedores de que os temas de gestão da política econômica não poderiam ser resolvidos no âmbito daquela instância - dadas as regras tácitas do colegiado, sob o pretexto de sua complexidade e governabilidade -, estabeleceram um pacto informal para evitar as agendas interditadas. Na prática, esse expediente impediu a deterioração das relações, entre empresários e o governo e dentro do próprio governo, ainda que a política de apreciação cambial, por exemplo, mantida com todo rigor nos primeiros anos do governo Lula, atingisse diretamente o interesse dos industriais dependentes de rendas de exportação. A capacidade de fazer uma triagem temática da agenda e evitar que os temas potencialmente conflitivos contaminassem a pauta não foi menos trivial. Uma habilidade básica dos empreendedores políticos era a de, a cada reunião do conselho, identificar temas potencialmente divergentes que representassem uma ameaça ao nível de cooperação inter pares, deslocando seu debate para outras arenas (negociações extraconselho) ou para ambiente informais (despachos bilaterais, agendas secundárias, outros colegiados etc.), neutralizando assim seu potencial desagregador.

As relações de relativa confiança mútua, geradas pelo desenho institucional e a frequência dos contatos, permitiu que a confidencialidade sobre os temas tratados evitasse comportamentos mais oportunistas como os dos rentistas (rent seekers $)^{8}$; de fato, nada indicava que aquela instância fosse utilizada para conquista e/ou manutenção de posições clientelistas ou privilégios autoaplicáveis a algum de seus membros. Há diversas condições para que a 
costumeiro e usual do termo (unproductive rent seeking) a política industrial pode discriminar a geração e apropriação de rendas propositalmente. Seria o caso, por exemplo, das premiações públicas para produtos inovadores.
${ }^{9}$ Diversos outros autores sustentam a importância vital de mecanismos de conectividade intensa entre governo e sociedade civil, onde os burocratas podem formular políticas públicas mais efetivas, numa governança mais experimental e interativa (Evans 2011; Rodrik 2007; Sabel 2004).

\section{II.2. Os casos analisados}

relação governo-empresas não degenere em comportamentos rentistas e de conluio. Conforme Maxfield e Schneider (1997), a credibilidade e reciprocidade, que reduz os custos de "incerteza política" e a confiança interpessoal, que implica dependência mútua da natureza, fluxo e qualidade das informações, estariam entre os principais fatores. Haveria também, segundo eles, diversos pressupostos que garantiriam essas condições: gestores públicos protegidos das pressões corporativas, democratização das relações Estado-Sociedade, transparência na percepção de custos e benefícios - condição básica de diálogo entre atores políticos e percepção comum de ameaças (como o processo de desindustrialização e desnacionalização). Sem isso, os custos da relação Estado-empresários superariam os benefícios esperados, transformando-se em "conversas inúteis" (cheap talk). Tais condições, de um modo geral, existiram no funcionamento do colegiado, pelo menos no período analisado.

As arenas ou instâncias colegiadas reunindo as partes interessadas em determinado assunto ou política pública são comuns em sistemas democráticos, especialmente quando o governo estimula em algum grau a participação das diversas clientelas como forma de legitimação política, melhoria da eficiência executória ou simplesmente como prestação de contas e transparência de gestão (Abers \& Keck 2008). As arenas de políticas podem assumir formas diversas. Em política industrial, ao contrário de impor algum custo deliberativo ou comprometer a eficácia da burocracia weberiana, as instâncias de coparticipação com o empresariado têm sido defendidas pelo resultado que podem produzir em termos de soluções coletivas mais robustas, consistentes e realistas. Tais instâncias, quando bem sucedidas, acabam adquirindo a função de organizar e racionalizar as demandas fragmentadas e contraditórias dos diversos grupos de pressão, diminuindo os custos políticos dos processos de barganha individual que é aprisionada por particularidades clientelísticas. ${ }^{9}$

O conceito de "arena", útil para entender a experiência concreta do CNDI no período inicial até 2007, é o definido por Ostrom (1990). Ao estudar as soluções para os problemas de ação coletiva, a autora estabeleceu nas "arenas de escolha" (arena of choice), uma unidade básica de análise política para discutir a dinâmica das relações entre os agentes na gestão de propriedades coletivas ou comuns a todos. Os atores estão inseridos naquilo que a autora chama de action situation, isto é, suas opções e estratégias são definidas pelas opções físicas, pelos atributos da comunidade em que estão inseridos e pelo ambiente institucional. Seu modelo de análise, conhecido como Análise Institucional e Desenvolvimento (Institutional Analysis and Development, IAD), procura entender os mecanismos que regulam o uso de recursos comuns e as diferentes perspectivas ou escalas de interação entre os atores (Ostrom 1990; 2005).

Objetiva-se testar a validade do marco teórico explicativo, em especial a ação de empreendedores políticos, a influência de novas ideias sobre desenvolvimento e política industrial e o tipo de relacionamento político estabelecido no interior da arena por seus participantes.

O método escolhido para o teste da hipótese de trabalho foi o estudo de caso, típico de pesquisas de natureza qualitativa, com adaptações. Esse método permite responder as questões que dialogam com as variáveis do marco teórico principal do trabalho (Ragin 1987). Nesse sentido, a pesquisa contribui com entendimento dos fatores de sucesso e fracasso de uma determinada política pública setorial em geral e do funcionamento das arenas de diálogo tripartite, em particular. 
${ }^{10}$ Os casos estudados foram os seguintes: (1) a criação da "Lei de Inovação" (assim denominada devido à sua congênere francesa); da (2)

"Lei do Bem" e (3) a reorganização dos "Fundos Setoriais" (modelo de governança), instrumentos de aplicação dos recursos do Fundo Nacional de Ciência e Tecnologia, o FNDCT. Os dados documentais podem ser checados em De Toni (2013).
Os casos concretos constituem processos retirados da agenda do CNDI, na medida em que representaram, a priori, temas onde potencialmente as questões de pesquisa poderiam (ou não) ser respondidas. A análise não se limitou ao estudo de documentos oficiais, mas também da percepção dos atores participantes nas entrevistas realizadas. As evidências documentais foram ponderadas por evidências testemunhais indicadas em De Toni (2013). A escolha dos casos procurou atender ao critério da multiplicidade de fontes e da longitudinalidade da agenda de política industrial que é, por si, complexa e extensa. Os processo selecionados refletem, também, os procedimentos de negociação e debate no interior do CNDI. Embora não estivessem confinados aos limites políticos ou institucionais da arena, o conselho foi decisivo para o desfecho ${ }^{10}$.

A narrativa sobre cada caso pretendeu apreender o contexto em que as trajetórias dos atores foram criando uma trama de eventos, processos e decisões. O método narrativo explica o fluxo de ações que singularizam cada caso, de modo a encadear os diversos eventos críticos que podem explicar o desfecho final de um processo decisório. Os eventos encadeados em trajetórias coerentes sinalizam um fio condutor para o relato, que reconstrói uma experiência passada, imprimindo um novo sentido que evidencia os mecanismos de ação daquele acontecimento, suas relações causais fundamentais (Barzelay \& Velarde, 2004; Tilly McAdam \& Tarrow 2008).

\section{A dinâmica de funcionamento das instâncias e processos: evidências empíricas}

\footnotetext{
11 "The factors affecting the structure of an action arena include three clusters of variables: (1) the rules used by participants to order their relationships, (2) the attributes of the biophysical world that are acted upon in these arenas, and (3) the structure of the more general community within which any particular arena is placed" (OSTROM et alii 1994, p.15).

12 Para Rua (2005, p.1), entende-se por coordenação técnico-política “[...] um conjunto de mecanismos e procedimentos destinados a compor ou articular as decisões e ações do conjunto de entes governamentais políticos e burocratas - de maneira a obter resultados concertados, intercomplementares e consistentes; ou seja: não-erráticos, não-superpostos e não-contraditórios, que expressem e façam sentido em um projeto de longo prazo".

13 Lindblom (1959), já havia abordado esse tema ao constatar que o processo decisório em políticas públicas é necessariamente fragmentado e não linear. Ao interagir os atores vão
}

Na literatura de gestão pública e de políticas públicas, o conceito de "coordenação" está associado à busca da eficiência administrativa ou organizacional. A ação coordenada implica racionalização de métodos e processos para o compartilhamento de objetivos e resultados ${ }^{11}$. Em políticas públicas, o atributo ou qualidade de "coordenação" dos atores implica também otimização da eficiência, entendida como relação entre insumos necessários e produtos gerados, de uma política qualquer, para a obtenção do resultado desejado, visto como impacto no problema a ser resolvido ${ }^{12}$. Aqui, trata-se de abordar um conceito mais amplo de coordenação relacionado ao processo político de cooperação e obtenção do consenso sobre temas necessariamente conflituosos, onde as dimensões técnicas e políticas são combinadas em doses variáveis. A coordenação de um governo, entendida como o alinhamento político de seus atores, implica sempre compartilhamento de objetivos e coerência entre os diversos resultados.

Um dos instrumentos típicos de uma ação coordenada é a deliberação colegiada, baseada no debate e na livre argumentação e persuasão entre os participantes de uma instância coletiva. Como as condições de igualdade entre os participantes e a simetria de informações são pressupostos dificilmente observáveis no mundo real, o processo de coordenação em fóruns colegiados tende a ser mais incremental, a partir de ajustes mútuos, muitas vezes, não lineares, nem sequenciais ${ }^{13}$.

A coordenação intragovernamental surge no ambiente do CNDI, não como um problema administrativo, nem como uma solução planejada a priori pelos seus empreendedores mais destacados, como o Ministro Furlan, ou pela burocracia técnica do MDIC. Ela surge exatamente da confluência de grandes fluxos políticos: problemas estruturais da indústria que ganham exposição pública crescente, políticas industriais alternativas vindas da burocracia técnica do governo e do setor privado e um ambiente político propício, estimulado pela coalizão governamental vencedora. Há uma "tecnologia" suportando esse arranjo cooperativo que não é trivial, conforme afirmava o então Ministro do Desenvolvimento, Indústria e Comércio Exterior, o principal empreendedor político nesse processo: 
"ajustando-se" reciprocamente em sucessivos e cumulativos processos de barganha, resultando numa evolução incremental.
"O CNDI, ele foi importante por que havia falta de um lócus adequado para que o governo e o setor privado dialogassem em torno de uma pauta sintética e objetiva. Que não ficasse poluído de representantes, então uma das coisas que eu notei logo no governo, é que [...] você tende a participar de tantos órgãos e que você acaba mandando representantes nas reuniões, inclusive órgãos que eu presidi, em que cada vez ia um representante de um ministério ou mesmo de uma federação ou confederação. Aí a produtividade cai violentamente, não existe compromisso entre as pessoas, não existe memória também por que se vê um representante que não veio a uma reunião anterior, ele está por fora de qualquer assunto! E o presidente concordou em criar um órgão pequeno [...] com reuniões bimensais. Tinha um calendário anual, portanto, ninguém podia dizer: 'olha fui surpreendido, nessa data não posso' [...] ter um calendário anual e você se organiza de acordo com as suas prioridades [...] então o terceiro ponto é que as reuniões teriam uma pauta muito sintética, três assuntos no máximo! E elas durariam duas horas com tolerância de 15 minutos [...]" (Luiz Furlan, entrevista concedida ao autor em 5 out. 2012).

E ainda:

"Porque em Brasília os atrasos são costumeiros, e também não tinha lugar fixo por ordem de importância. Os assentos vieram embaralhado e não se punha um ministro ao lado do outro, nem um do setor privado [...] se alternava. Um do setor privado, um do setor público [...] e não eram os mesmos sempre. Trocava de lado. Para não formar panelinhas, então acho que funcionou bastante bem. Foram raríssimas [as] ocasiões que tivemos que remarcar [as] datas, uma ou duas vezes se não me engano [...]. Os ministros passaram a valorizar essa possibilidade de um diálogo franco em torno de apresentações relevantes, porque os dois primeiros tópicos eram de apresentações de prioridades e depois havia um debate em que cada uma podia usar a palavra por dois minutos. E a mim cabia, infelizmente ou felizmente, dar disciplina e andamento para a reunião e dizer: 'olha, se você falar mais que dois minutos, a reunião não vai terminar no horário e as pessoas vão embora e nós não cumprimos a nossa tarefa'. Então houve um período de aprendizado e a partir daí funcionou muito bem. Disciplina é uma capacidade também de afrontar até os egos das pessoas e dizer: 'olha, o seu tempo terminou"' (idem).

Em relação às políticas públicas, o CNDI transforma a agenda formal ideal das políticas industrial (a PITCE e a PDP), numa "agenda decisional" de acordos possíveis, filtrando os principais projetos e iniciativas segundo sua viabilidade tecnopolítica conjuntural. $\mathrm{O}$ ativismo estatal resultante dessa condição de cooperação público-privada aparece nitidamente em três casos: na construção da chamada "Lei da Inovação", na "Lei do Bem" e nas mudanças regulatórias da gestão dos Fundos Setoriais. Esses três processos têm seus conteúdos fortemente relacionados às pautas da política industrial e serão detalhados na sequência deste artigo.

A chamada "Lei de Inovação" (Lei 10 973/2004) foi debatida no CNDI nas três reuniões que antecederam a formalização do conselho (duas em 2004 e uma em 2003), aparecendo em diversas entrevistas dos participantes e envolvidos no tema. A "Lei do Bem", complementar à primeira, entrou na agenda na sequência, em 2005. A principal e grande novidade da lei foi a maior flexibilidade na relação entre os Institutos de Ciência e Tecnologia (ICTs) e entre o setor privado, as universidades e as entidades sem fins lucrativos. Por exemplo, a lei permitiu: $(i)$ aos pesquisadores de ICTs públicos, o afastamento temporário para colaboração com outras ICTs públicas e privadas; (ii) a transferência de tecnologia e licenciamento de invenções para novos produtos e serviços pelo setor privado sem a necessidade licitação pública, além de (iii) criar mecanismos de subvenção pública direta para empresas inovadoras. A lei provocou uma ruptura conceitual na cultura jurídica pública que praticamente criminalizava o uso de recursos públicos pelo setor privado, independente da finalidade ou condicionalidades. Em 2006, a Finep lançou a primeira chamada pública para 
${ }^{14}$ A dissociação entre C \& T e o aparelho produtivo industrial não é recente, ao contrário, como afirma Delgado (2010), o problema é antigo: a montagem de um sistema nacional de ciência e tecnologia, iniciado nos anos cinquenta e ampliado nas décadas seguintes, especialmente nos anos 1970, permaneceu dissociado do setor produtivo.

15 Já havia projetos incipientes nessa linha, entre eles o Programa de Inovação Tecnológica em Pequenas Empresas, de 1997; o Programa de Apoio à Pesquisa em Empresas (PAPPE) da Finep; o Programa de Capacitação de Recursos Humanos para Atividades Estratégicas (RHAE) do CNPq; a "Lei de Informática" que dá incentivos em troca do investimento mínimo de 5\% do faturamento em P\&D e os próprios Fundos Setoriais que operavam desde 1997.

${ }^{16} \mathrm{O}$ consenso superou as fronteiras políticas do próprio governo Lula. Carlos Pacheco, professor do Instituto de Economia da Unicamp e ex-dirigente do MCT durante subvenção de R 300 milhões para atender aos objetivos denominados "opções estratégicas" da PITCE. Entre os produtos prioritários para receber recursos a fundo perdido para pesquisa, estavam os sistemas de TV digital, sistemas de identificação automática de pessoas, produção do fármaco AZT, óleos vegetais de alto rendimento, nanotecnologia, biotecnologia e energias alternativas. Foram apresentados 1099 projetos de 900 empresas com demandas de quase $\mathrm{R} \$ 2$ bilhões, foram selecionados 70 projetos que receberam $\mathrm{R} \$ 145$ milhões em 2007.

Dois anos depois, a segunda chamada pública receberia 2500 projetos totalizando R\$ 6 bilhões de demanda, três vezes mais. No terceiro ciclo de avaliação do impacto da subvenção econômica, a FINEP chegou à conclusão de que $93 \%$ das empresas beneficiadas aportaram aos projetos o mesmo montante de recursos recebidos, $30 \%$ das tecnologias desenvolvidas tinham alcance mundial e $52 \%$ das empresas tinham sido bem sucedidas no lançamento de inovações (Finep 2012).

A "Lei de Inovação" foi uma quebra de paradigma no modo como o governo brasileiro tratava o tema. O debate não foi pacífico no início do governo Lula. Havia um receio, por parte da burocracia do MCT, de perda de autonomia das universidades e seus ICTs e da própria criação científica como um todo (Giesteira 2010). Antes mesmo do CNDI, o tema foi duramente debatido na "Câmara de Política Econômica", órgão interno do governo, reunindo ministros da área econômica. Nesse fórum, a possibilidade de remunerar pesquisadores públicos em empresas privados já havia sido admitido pelo Ministério da Fazenda. Foi fundamental a percepção do ministro Eduardo Campos do MCT, que não tinha origem na academia, para a necessidade de orientar a pesquisa científica para as demandas da indústria aumentando os projetos cooperativos e diminuído a lógica vinculacionista ${ }^{14}$. No MDIC, Luis Furlan, seguido pelos empresários industriais, acreditava que o modelo linear de inovação ou science push, baseado na concentração de incentivos à universidades públicas e bolsas de mestrado e doutorado, havia sido insuficiente para aumentar a competitividade das empresas. A ideia subjacente na PITCE de 2004 era de que a inovação deveria ser incrementada no setor privado a partir da cooperação Estado-empresa ${ }^{15}$. As novas ideias sobre desenvolvimento já criaram uma orientação geral de que o problema brasileiro nesse campo não era a ausência de recursos ou incentivos, mas a falta de arranjos institucionais que garantam impactos concretos da inovação nas empresas e nos mercados. Os debates no interior do CNDI foram praticamente consensuais, concentrando-se nas diretrizes estratégicas da lei ${ }^{16}$. Assim como o Bay-Dole Act nos Estados Unidos, de 1980 (que estimula a transferência de tecnologia para as empresas), a "Lei de Inovação" implicou desde sua aprovação uma mudança de paradigma e cultura nas universidades públicas federais, até então hostis à cooperação tecnológica com o setor privado. A Lei 10 973/04 - resultado direto das novas ideias sobre política industrial - enfrentou a cultura institucional, burocrática e legal que entrava a cooperação público-privada em inovação. Entre as suas medidas, a concessão de recursos para a subvenção econômica, a preferência na aquisição de bens e serviços públicos de empresas que invistam em P\&D no país e a autorização para que a União participe do capital de empresa privada com processos inovadores são aspectos relevantes nessa quebra de paradigma. Outro marco da lei foi a autorização para ambientes cooperativos (prestação de serviços, parcerias para pesquisa conjunta, uso compartilhado de laboratórios públicos etc.), com possibilidade de pagamento aos criadores de inovação com as receitas próprias derivadas, com remuneração adicional ao pesquisador. Em 2008 já havia 54 Núcleos de Inovação Tecnológica (NITs), instâncias acadêmicas dos ICTs que articulam a cooperação privada, instalados. 
o governo Cardoso, afirmou que "o balanço é muito positivo [...] fez o país despertar para o tema" (Souza, Mol \& Pacheco 2009).

\footnotetext{
${ }^{17}$ Entre os principais instrumentos estão os seguintes: deduções de Imposto de Renda e da Contribuição sobre o Lucro Líquido - CSLL de dispêndios efetuados em atividades de $\mathrm{P} \& \mathrm{D}$; a redução do Imposto sobre Produtos Industrializados - IPI na compra de máquinas e equipamentos; depreciação acelerada desses bens; amortização acelerada de bens intangíveis; redução do Imposto de Renda retido na fonte incidente sobre remessa ao exterior, resultantes de contratos de transferência de tecnologia; isenção do Imposto de Renda retido na fonte nas remessas efetuadas para o exterior, destinada ao registro e manutenção de marcas, patentes e cultivares. ${ }^{18}$ O processo inverso é chamado pela literatura econômica de crowding out, que indica o quanto as empresas investiriam em $\mathrm{P} \& \mathrm{D}$ no mesmo montante que fariam, independentemente da existência do incentivo. ${ }^{19}$ As empresas de grande porte dominam o uso do benefício já que a "Lei do Bem" só atende empresas que apuram pelo método do "lucro real", enquanto as de menor
}

Tanto a "Lei de Inovação" como a "Lei do Bem" foram sínteses de movimentos institucionais e políticos que iniciaram mesmo antes do governo Lula, ainda que só as condições de concertação política do governo Lula tenham possibilitado a formalização de um novo marco regulatório. Desde o segundo governo Cardoso havia grupos de trabalho criados pelo MCT na gestão do ministro Ronaldo Sardenberg e diversos temas que foram incorporados à lei já haviam vindo à público na Conferência Nacional de Ciência e Tecnologia, de 2001 (Dudziak 2007). Um projeto de lei chegou a ser enviado ao Congresso no final do governo Cardoso, em 2002, mas foi inviável sua votação naquele ano e foi retirado de pauta pelo Executivo.

A "Lei de Inovação" e seus 28 artigos, resultado combinado da ação de empreendedores políticos evidenciou como novas ideias, em circunstâncias específicas, podem quebrar paradigmas. A inovação e a criação de redes público-privadas está no centro das novas políticas industriais, como já foi evidenciado anteriormente na exposição sobre a PITCE, a política industrial do primeiro governo Lula. Temas como as condições dos pesquisadores nas universidades, aspectos remuneratórios e esquemas de trabalho, a relação mantida com as instituições de pesquisa, direitos de propriedade e licenciamento de patentes e invenções e a cessão de laboratórios eram considerados tabus. Não havia um marco regulatório antes da lei que viabilizasse o uso privado de recursos públicos, por um lado, e o uso público (pelos ICTs) dos resultados de inovações e novos desenvolvimentos.

A chamada "Lei do Bem" (Lei 11 196/2005), também discutida profundamente no CNDI em 2004 e 2005, criou uma série de incentivos para o investimento em inovação complementares à "Lei de Inovação"17. O objetivo desses incentivos sempre foi gerar um fenômeno chamado de crowding in, quando o incentivo estimula o investimento privado superior ao que teria sido se o incentivo não existisse, o que sempre é o resultado mais desejável ${ }^{18}$. A "Lei do Bem" complementou e regulamentou os instrumentos da "Lei de Inovação". Antes disso, os incentivos fiscais seguiam a legislação dos anos 1990 (dos PDTIs e PDTAs). A maior novidade foi a simplificação de procedimentos e não exigir a pré-aprovação de projetos. As empresas enviam ao MCTI, por meio eletrônico, as informações dos seus programas de P\&D e podem excluir, da apuração do lucro líquido, diversos itens que gerariam uma redução significativa do Imposto de Renda (despesas operacionais, pessoal, patentes etcc.) ${ }^{19}$.

Em pesquisa feita pelo IPEA, em 2008, utilizando a base da PINTEC de 2005 (IPEA 2010) ficou demonstrado que a lei ajudou a consolidar setores de forte competitividade, apesar de não conseguir estimular a diversificação setorial (a maior parte dos beneficiários estão na indústria automobilística, petroquímica e aeronáutica $)^{20}$.

O processo de negociação desses novos instrumentos legais deve ser entendido a partir da força das novas ideias do governo Lula. Havia um consenso dentro do governo, sobretudo no então Ministério de Ciência e Tecnologia dirigido por Eduardo Campos (um quadro político do PSB que não tinha vínculo orgânico com as corporações acadêmicas), de que o sistema de inovação brasileiro padecia pela ausência de conexões mais virtuosas e produtivas entre o setor público e privado. As conferências nacionais de ciência e tecnologia também haviam detectado esse gargalo estrutural e, nos demais ministérios envolvidos, em especial no MDIC, já havia a ideia consolidada de que a mudança do marco legal era medida imprescindível para solucionar o problema. Não houve resistência institucional significativa das organizações do sistema de inovação.

O Fundo Nacional de Desenvolvimento Científico e Tecnológico (FNDCT) foi criado, em 1969, como instrumento financeiro de integração da ciência e 
porte usam o método do "lucro presumido".

${ }^{20}$ Segundo De Negri (2012):

"A lei de Inovação, de 2004, e a chamada "Lei do Bem", de

2005, efetivamente

constituíram marcos

importantes na evolução das

políticas de inovação no Brasil

[...] Atualmente, mais de 600

empresas utilizam os

benefícios fiscais dessa lei

para realizar inovação. Parece

pouco, mas essas empresas

representam parcela

significativa do total investido

em $P \& D$ no país, dado que

essas empresas investiram, em

2009, R \$ 8,3 bilhões em

P\&D” (p.19).

21 Por exemplo, o Fundo

Setorial Espacial tem 25\% dos

recursos das receitas de

utilização de posições orbitais,

$25 \%$ das receitas da União

auferidas em lançamentos

comerciais de satélites e

foguetes e $25 \%$ das receitas

auferidas pela comercialização

de dados e imagens de

rastreamento, telemedidas e

outras. O Fundo Setorial de

Energia tem $0,4 \%$ do

faturamento líquido das

concessionárias de geração,

transmissão e distribuição de

energia elétrica, o Fundo de

Informática recebe $0,5 \%$ do

faturamento bruto de empresas

incentivadas pela Lei de

Informática e assim por diante.

${ }^{22}$ Alvarenga, Pianto e Araújo

(2010) estudaram 344

empresas que acessaram e

cerca de 113 mil empresas que

não acessaram os Fundos

Setoriais, entre 2001 e 2007, e

demonstraram que, em média,

para cada $1 \%$ a mais de

recursos para as firmas que

acessaram, há 5\% mais firmas

que não acessaram no ano

seguinte. tecnologia com a política de desenvolvimento nacional, com base no Funtec (Fundo de Apoio à Tecnologia), criado em 1964 e gerido pelo BNDES. A Finep (Financiadora de Estudos e Projetos), criada em 1967, é a secretaria executiva do FNDCT desde 1971. A partir dos anos 1970 o FNDCT tornou-se o mais importante instrumento de financiamento para a pesquisa e a pós-graduação na expansão do sistema de Ciência, Tecnologia \& Inovação nacional. Os problemas de restrição de crédito e perda de reservas, o aumento da taxa de juros e os cortes orçamentários nos anos 1980 e 1990 comprometeram muito a execução e implementação do fundo. Em 1999, a criação dos Fundos Setoriais, decorrentes de um processo de gestão e financiamento inovador ${ }^{21}$, envolvendo contribuições públicas e privadas, contribuiu para a revitalização e capitalização do FNDCT. O primeiro fundo setorial criado foi o CT-PETRO, seguidos de outros. Atualmente operam 18 fundos (Finep 2011). Durante a década de 2000 os Fundos Setoriais incrementaram dramaticamente seu orçamento devido ao não contingenciamento orçamentário desde 2003, gerando resultados concretos quanto ao aumento da taxa de inovação no país ${ }^{22}$.

Ao longo de 2005 e 2007 o CNDI, em paralelo às instâncias do Sistema Nacional de Ciência e Tecnologia, coordenado pelo MCT, discutiu profundamente as condições de integração das políticas industriais e tecnológicos, sobretudo na destinação de recursos para as prioridades da política industrial nacional.

Como assinala um ex-dirigente do MCT e da Finep durante os governos de Lula:

\begin{abstract}
"Você não tinha uma visão sistêmica de promoção da inovação, a própria lógica era uma definição setorial, o planejamento era dado setorialmente. Isso não resolvia ou não ajudava a ter uma visão sistêmica e uma iniciativa estruturante. Justamente no mesmo período em que se estruturou a maior política industrial foi promovida uma alteração do sistema de governança dos fundos setoriais que deixaram de ser geridos de forma segmentada ou setorial e foi montada uma gestão centralizada disso para poder focar os grandes objetivos estratégicos nacionais nos quais se inseriam os objetivos da política industrial... Na medida em que se estruturou uma política industrial você tem uma confluência de atores muito importante, tinha o IPEA..., no MDIC, além do Furlan, você tinha o Roberto Jaguaribe na Secretaria de Tecnologia Industrial [transformada em Secretaria da Inovação em 2010], com uma visão aberta para isso, aqui no MCT, tanto do Sérgio Rezende na presidência da FINEP quanto do ministro Eduardo Campos...com uma agenda de desenvolvimento comum entre eles" (Entrevista ao autor 16 de Julho de 2013, De Toni, 2013, p. 384).
\end{abstract}

As reuniões do CNDI costumavam ser o desfecho para decisões que estavam em debate em outros fóruns do governo e do setor privado. Assim, em 25 de outubro de 2005 , durante a $5^{\mathrm{a}}$ reunião ordinária do conselho, foi apresentado um longo estudo coordenado pela ABDI sobre a situação dos fundos do governo, entre os quais os Fundos Setoriais. Um dos elementos problemáticos apontados, a pulverização dos recursos e a baixa aderência às estratégias industriais, foi central no processo de revisão do FNDCT que culminou em nova legislação em 2007. Assim também durante a $2^{\mathrm{a}}$ reunião extraordinária do Conselho, em 21 de setembro de 2006, após a apresentação técnica do IPEA sobre a situação de inovação no Brasil, pela pesquisadora Fernanda De Negri, o conselheiro Paulo Godoy, da indústria de base (ABDIB), fez um forte apelo para aumentar a disponibilidade de recursos dos fundos para as empresas. A integração progressiva entre as políticas do MDIC e do MCT foram registradas no Relatório de Gestão dos Fundos Setoriais de 2011:

"Nesse contexto, utilizaram-se como base para o alcance das metas para operação dos recursos do FNDCT, definidas no PPA 2008-2011, as seguintes orientações:

(i) Plano de Ação de Ciência, Tecnologia e Inovação - PACTI 2007-2010; 
${ }^{23}$ As ações específicas para apoiar as prioridades da PITCE estão detalhadas no Relatório de Gestão dos Fundos Setoriais (2011). (ii) Diretrizes (ou atividades estruturantes) que antecederam a formulação da Estratégia Nacional de Ciência, Tecnologia e Inovação (ENCTI) 2012-2015, aprovada pelo Conselho Nacional de Ciência e Tecnologia (CCT) em dezembro de 2011, sucessora do PACTI 2007-2010;

(iii) Política de Desenvolvimento Produtivo (PDP), lançada em 2008;

(iv) Diretrizes emanadas pela Política Industrial consubstanciada no Plano Brasil Maior-PBM 2011/2014, instituído pelo Decreto $n^{\circ} 7.540$ de 02/08/2011, sucessor da PDP.

Trata-se de políticas públicas estreitamente articuladas com vistas à promoção da competitividade sistêmica da economia brasileira, e cuja meta conjunta para 2014 é ampliar o investimento empresarial em P\&D para 0,9\% do PIB, mediante diversas ações, tais como: o aperfeiçoamento do marco legal; o fortalecimento do Sistema Nacional de C,T\&I e de sua base de sustentação (recursos humanos, pesquisa e infraestrutura tecnológica); a integração de diferentes instrumentos de apoio à C,T\&I existentes no país; a estruturação de programas prioritários, dentre outras (Finep 2011, p.15; sem grifos no original).

Diversas ações transversais - geridas pelo Comitê de Coordenação dos Fundos Setoriais - foram criadas por conta da integração com a política industrial (previstas pela Lei 11540 de 2007), priorizando a aplicação nas cadeias produtivas elencadas pela PDP e ações horizontais como a subvenção econômica, a equalização de taxa de juros para inovação, o apoio à empresas de base tecnológica, a implementação de instrumentos de garantia de liquidez e a subvenção à remuneração de pesquisadores empregados em atividades de inovação ${ }^{23}$. As ações transversais, sobretudo através da modalidade de encomendas tecnológicas, tiveram impacto fundamental no fortalecimento da infraestrutura científica e tecnológica, em particular em ICTs e laboratórios públicos (Nascimento \& Oliveira 2011). Outro dispositivo debatido no CNDI foi a necessidade de diferenciação regional da aplicação dos recursos. Nesse sentido a nova regulamentação do FNDCT previu aplicação diferenciada para as regiões Norte, Nordeste e Centro-Oeste. O realinhamento gerado pelo novo modelo de gestão dos Fundos Setoriais - por influência da nova política industrial - foi registrado pela Mensagem Presidencial ao Congresso no ano de 2006:

A estruturação do novo modelo de gestão dos Fundos Setoriais permitiu focar na PITCE cerca de $60 \%$ dos recursos disponíveis para novos investimentos desses Fundos, em 2005. Agrega-se a isto os créditos reembolsáveis estendidos a empresas pela Financiadora de Estudos e Projetos (FINEP) para fomentar atividades de pesquisa e desenvolvimento. O novo modelo de gestão aumentou a eficiência na execução dos recursos dos Fundos [...] (Mensagem ao Congresso Nacional, 2006, p. 27, grifo nosso)

[...] a implementação de novo modelo de gestão integrada dos Fundos Setoriais, que se constituem no principal instrumento de fomento do Governo para essa área. O novo modelo, a ser consolidado na regulamentação definitiva do FNDCT, permitiu integrar grande parte dos investimentos dos Fundos através de ações transversais alinhadas com as prioridades do Governo, evitando a duplicidade ou dispersão de iniciativas e assegurando maior transparência e eficiência na execução dos recursos. (Mensagem ao Congresso Nacional, 2006, p. 85 , grifo nosso)

O processo de negociação, nesse caso, também deve ser entendido como resultado na hegemonia das ideias desenvolvimentistas que demandavam a reforma do marco legal e institucional dos instrumentos de apoio à inovação no país. As profundas mudanças no sistema de gestão com a nova Lei do FNDCT, em 2007, como a criação do Conselho Diretor, integrando o setor empresarial com o setor acadêmico (um dos dilemas do campo de C\&T), a formalização das ações transversais e dos comitês gestores de coordenação setoriais foram fundamentais para o alinhamento desse dispositivo com os objetivos da PI. A presença de entidades empresariais, do MDIC, da Embrapa e do BNDES no Conselho Diretor formalizou a estratégia de aderência dos fundos à política in- 
dustrial. A dinâmica do colegiado contribuiu positivamente para a mudança do modelo de governança dos Fundos Setoriais, considerando a legitimidade e o respaldo criado pelo conselho para coordenação com a área de ciência e tecnologia. Esse passo foi fundamental para aproximar as estruturas de financiamento de $\mathrm{P} \& \mathrm{D}$ das demandas reais das cadeias produtivas e minimizar o padrão histórico centrado quase que exclusivamente em ICTs públicos e na pesquisa básica. Após as mudanças, os recursos destinados aos fundos sofreram um profundo descontingenciamento financeiro pelo Ministério da Fazenda, atingindo os níveis mais altos de desembolso desde sua criação.

Estudos comprovam que os incentivos dados pela "Lei do Bem" geraram um aumento do dispêndio em P\&D em média entre 7\% a 11\% (Kannebley \& Porto 2012). Os autores avaliam que as mudanças nos marcos regulatórios ocorridas em meados dos anos 2000 contribuíram positivamente na manutenção e continuidade dos investimos, permitindo o financiamento de projetos com maior risco tecnológico. De fato, os dispêndios em ciência e tecnologia como proporção do PIB saltaram de $1 \%$ no ano 2000 para 1,13\% em 2008. Entre 2006 e 2010, último ano do segundo governo Lula, as empresas beneficiadas pelos incentivos cresceram $391 \%$, abrangendo aproximadamente $11 \%$ do total de empresas que realizam atividades de P\&D, segundo o IBGE (Pintec). Os dispêndios no mesmo período subiram 396\%. É provável que o debate sobre os marcos regulatórios no CNDI tenham contribuído para influenciar a mudança do patamar de gasto público e privado nessa área, como demonstra o Gráfico 1 a seguir.

Em relação à evolução dos desembolsos da Financiadora de Estudos e Projetos, a FINP, que é a agência brasileira de inovação, pode-se observar uma mudança de patamar no nível dos desembolsos financeiros a partir de 2004 e

Gráfico 1 - Evolução dos gastos em Pesquisa \& Desenvolvimento 2000 -2011 (em milhões de R\$ de 2011)

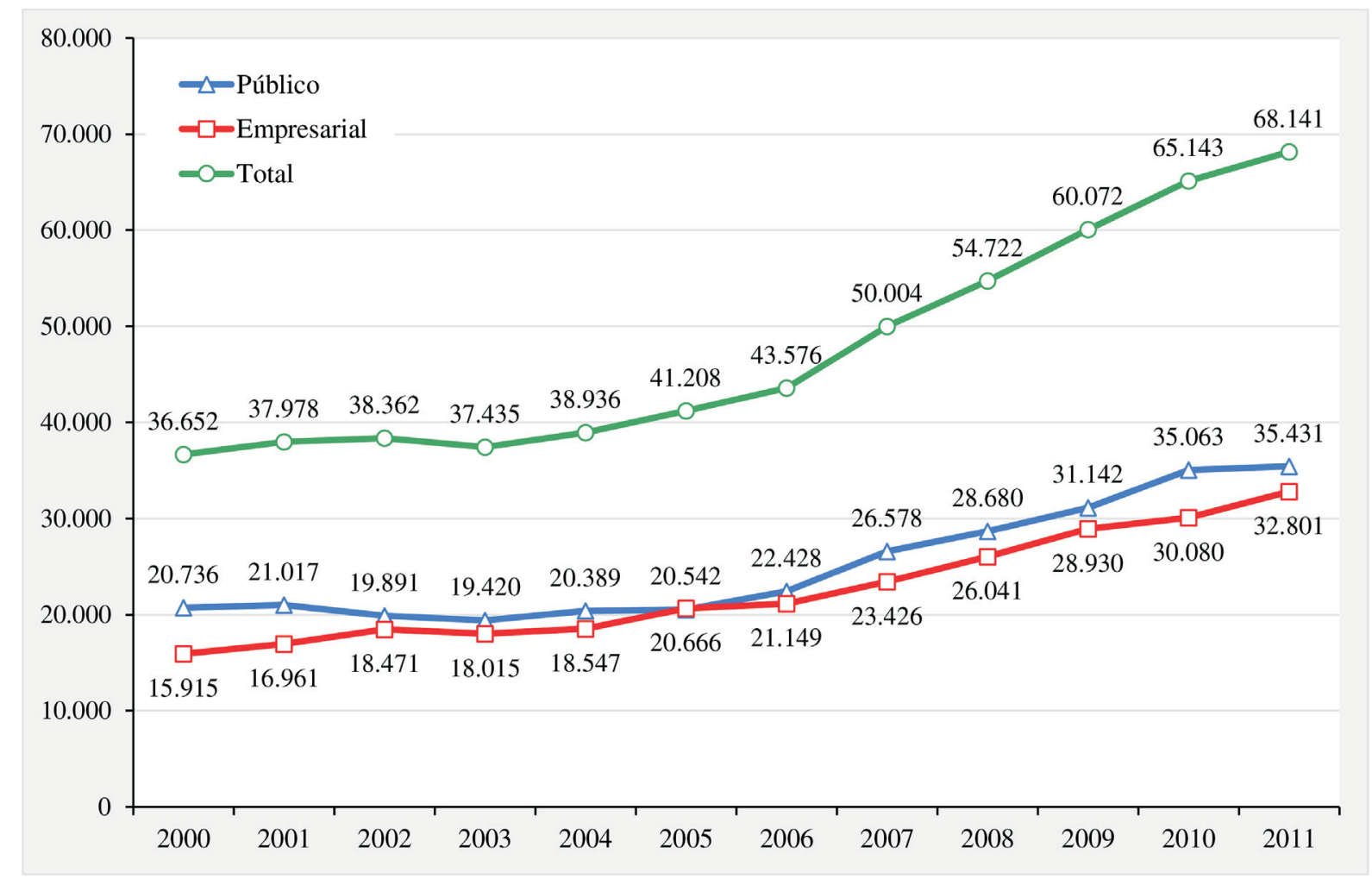

Fonte: Finep (2012). 
${ }^{24}$ Mecanismo trabalhado em Schneider (2010); Velde (2006); Camp e Root (1996) e Herzberg e Wright (2005).
2005, em especial dos recursos vinculados ao Fundo Nacional de Ciência e Tecnologia, o FNDCT (Gráfico 2).

No caso dos processos envolvendo a "Lei de Inovação", a "Lei do Bem" e os "Fundos Setoriais", pode-se avaliar a formulação da política industrial e o modus operandi dos atores envolvidos a partir do critério dos positive feedback loops $^{24}$, ou seja, decisões objetivas, claras e mensuráveis do CNDI efetivadas, no caso, através da elaboração de Medidas Provisórias que foram convertidas em leis pelo Congresso Nacional e da alteração de marcos regulatórios infralegais e procedimentos administrativos. A natureza dos temas debatidos no CNDI, pela sua complexidade, impacto e relação direta com a política industrial evidenciam a natureza do próprio colégio e o tipo de relacionamento estabelecido pela sua dinâmica. A seguir, uma relação selecionada dos principais temas que ocuparam a vida do conselho no seu período mais fértil (Tabela 1).

\section{Conclusões}

Desde a redemocratização brasileira não são poucas as críticas ao estilo manipulatório e instrumental do Estado ao convocar a sociedade para participar de arenas tripartites, no âmbito da formulação e implementação de políticas públicas. Nesse cenário, chama a atenção um breve período de funcionamento do Conselho Nacional de Desenvolvimento Industrial (CNDI), do ano que foi fundado (2004) até o final do primeiro mandato de Lula, em 2006. O colegiado contribui para criar as condições para a exposição pública e maior transparência de um setor social que historicamente utilizou estratégias mais sutis de acesso ao processo decisório estatal, os líderes empresariais industriais. A defesa de interesses do capital industrial naquele fórum, entretanto, parece não ter impli-

Gráfico 2 - Evolução dos gastos da FINEP 1999-2010 (R\$ milhões)

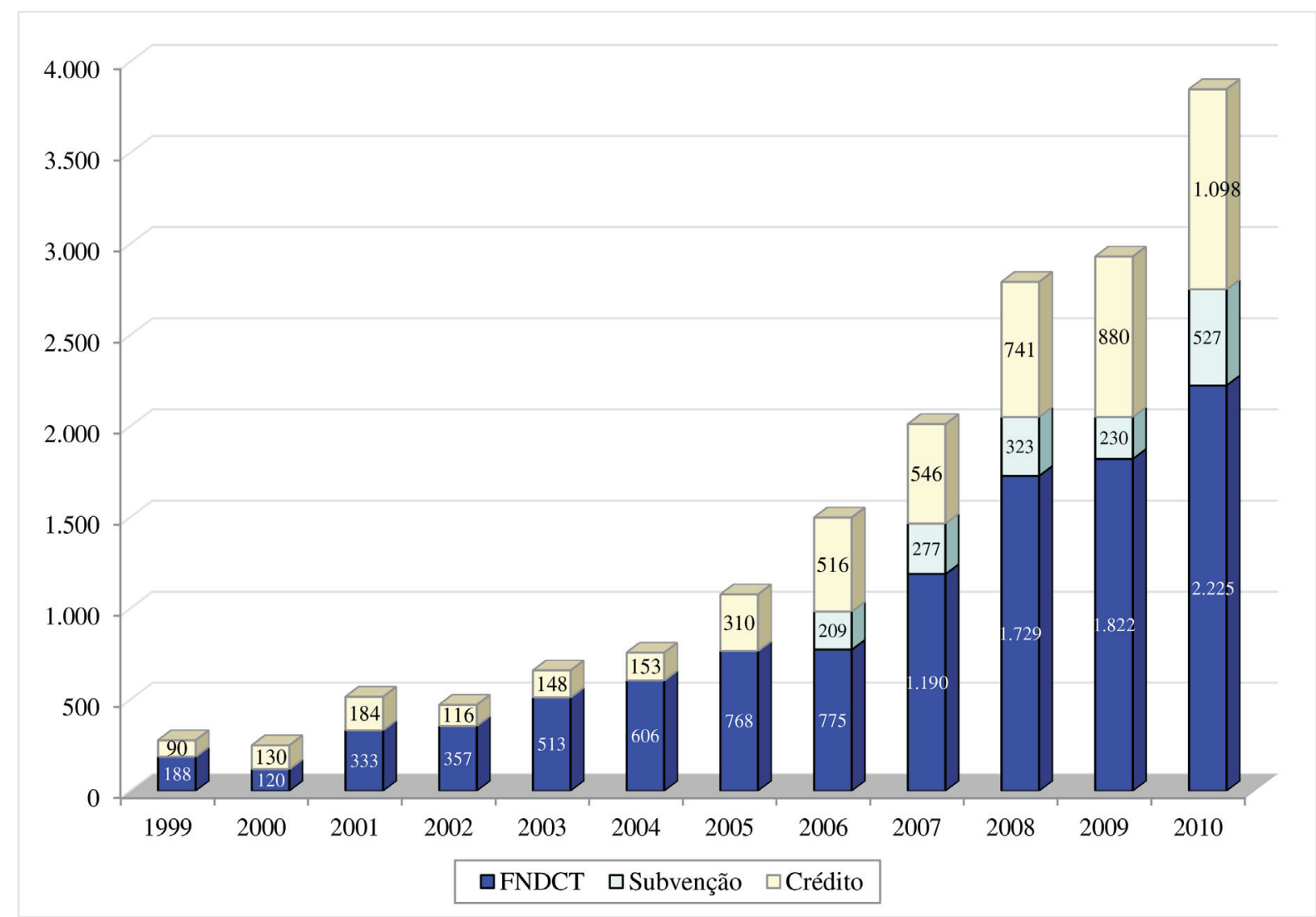

Fonte: Finep (2012). 
Tabela 1 - Principais temas debatidos e/ou encaminhados pelo CNDI 2004 - 2009

\begin{tabular}{|c|c|}
\hline Ano & Tema \\
\hline \multirow[t]{11}{*}{2004} & 1. Criação do Comitê de Financiamento e Garantia das Exportações - COFIG (Decreto 4 993, de 18 fev. 2004) \\
\hline & 2. Lançamento da Política Industrial, Tecnológica e de Comércio Exterior - PITCE (31 mar. 2004) \\
\hline & 3. Criação do PROFARMA/BNDES (maio 2004) \\
\hline & $\begin{array}{l}\text { 4. Criação do Grupo de Trabalho Permanente para Arranjos Produtivos Locais - GTP-APL (Portaria } \\
\text { Interministerial 200, de } 3 \text { ago. 2004) }\end{array}$ \\
\hline & 5. Debate sobre a reestruturação do INPI (Instituto Nacional de Propriedade Industrial) \\
\hline & 6. Criação da Empresa Brasileira de Hemoderivados e Biotecnologia - HEMOBRÁS (Lei 10 972, de 2 dez. 2004) \\
\hline & 7.Aprovação da “Lei de Inovação" (Lei 10.973, de 02/12/04; regulamentada pelo Decreto 5.563, de 11/10/05) \\
\hline & $\begin{array}{l}\text { 8. Instituição do Regime Tributário para Incentivo à Modernização e à Ampliação da estrutura Portuária - } \\
\text { REPORTO (Lei 11.033, de 21/12/04) }\end{array}$ \\
\hline & $\begin{array}{l}\text { 9. Criação (formal) do Conselho Nacional de Desenvolvimento Industrial-CNDI e da Agência Brasileira de } \\
\text { Desenvolvimento Industrial-ABDI (Lei 11.080, de 30/12/04; regulamentados pelos Decretos } 5.352 \text { e } 5.353 \text {, de } \\
\text { 24/01/05) }\end{array}$ \\
\hline & $\begin{array}{l}\text { 10. Debate sobre a nova Lei de Informática (Lei } 11 \text { 077, de } 30 \text { dez. 2004; regulamentada pelo Decreto 5.906, de } \\
26 \text { set. 2006) }\end{array}$ \\
\hline & 11. Debate sobre a nova lei das Parcerias Público-Privadas - PPP (Lei 11 079, de 30 dez. 2004) \\
\hline \multirow[t]{8}{*}{2005} & 12. Debate sobre a introdução do biodiesel na matriz energética brasileira (Lei 11 097, de 13 jan. 2005) \\
\hline & 13. Debate sobre a aprovação da Lei de Biossegurança (Lei 11 105, de 24 mar. 2005) \\
\hline & 14. Entrada em operação do quadro técnico da ABDI (jul. 2005) \\
\hline & 15. Redução a zero das alíquotas de IPI para bens de capital (Decreto 5 468, de 15 jun. 2005) \\
\hline & $\begin{array}{l}\text { 16. Formulação da “Lei do Bem” (Lei } 11 \text { 196, de } 21 \text { nov. 2005; regulamentada pelo Decreto } 5 \text { 798, de } 07 \text { jul. } \\
\text { 2006) }\end{array}$ \\
\hline & $\begin{array}{l}\text { 17. Instituição do Regime Especial de Tributação para a Plataforma de Exportação de Serviços de Tecnologia da } \\
\text { Informação - REPES (Lei } 11 \text { 196, de } 21 \text { nov. 2005) }\end{array}$ \\
\hline & $\begin{array}{l}\text { 18. Regulamentação do Regime Especial de Aquisição de Bens de Capital para Empresas Exportadoras - RECAP } \\
\text { (Decreto } 5 \text { 649, de } 29 \text { dez. 2005) }\end{array}$ \\
\hline & 19. Criação da Secretaria de Comércio e Serviços do MDIC \\
\hline \multirow[t]{3}{*}{2006} & 20. Criação da Rede Nacional de Agentes de Política Industrial-RENAPI (abr. 2006) \\
\hline & 21. Criação do Sistema Brasileiro de Televisão Digital - SBTVD-T (Decreto 5 820, de 29 jun. 2006) \\
\hline & $\begin{array}{l}\text { 22. Debate sobre o lançamento da Lei Geral da Microempresa e Empresa de Pequeno Porte (Lei Complementar } \\
\text { 123, de } 14 \text { dez. 2006) }\end{array}$ \\
\hline
\end{tabular}

2007 23. Lançamento da Política de Desenvolvimento da Biotecnologia (08 fev. 2007)

24. Criação do Comitê Nacional de Biotecnologia - CNB (Decreto 6 041, 08 fev. 2007)

25. Criação do Programa de Apoio ao Desenvolvimento Tecnológico da Indústria de Semicondutores - PADIS (Lei 11 484, de 31 maio 2007)

26. Programa de Apoio ao Desenvolvimento Tecnológico da Indústria de Equipamentos para a TV DigitalPATVD (Lei 11 484, de 31 maio 2007)

27. Debate sobre o Plano de Ação, Ciência e Tecnologia (PACTI) pelo MCT (nov. 2007)

28. Implementação do Novo PROFARMA/BNDES (nov. 2007)

29. Instituição do Sistema Brasileiro de Tecnologia - SIBRATEC (Decreto 6 259, de 20 nov. 2007)

30. Criação da Rede Nacional para a Simplificação do Registro e da Legalização de Empresas e Negócios REDESIM (Lei 11 598, 03 dez. 2007)

2008 31. Lançamento da Política de Desenvolvimento Produtivo - PDP (12 maio 2008)

32. Fortalecimento dos Fóruns de Competitividade para a implementação da PDP

33. Criação do Cadastro Nacional de Empresas

34. Debate sobre a criação da figura jurídica do Microempreendedor Individual - MEI LC n. 128) 


\begin{tabular}{ll}
\hline Ano $\quad$ Tema \\
\hline \\
35. Debate sobre a criação do Centro Nacional de Tecnologia Eletrônica Avançada - CEITEC S.A. (Lei 11 \\
894, de 29 dez. 2008) \\
36. Novo marco regulatório para Zonas de Processamento de Exportações (Lei 11 732, de 30 jun. 2008; Decreto 6 \\
634, de 05 nov. 2008) \\
37. Debate sobre a Estratégia Brasileira de Exportações (03 set. 2008) \\
38. Criação do Programa de Sustentação ao Investimento (PSI) - BNDES/MF \\
39. Criação do BNDES Pró-Engenharia (jun. 2009) \\
40. Debate sobre a instituição do Programa Nacional de Apoio à Inclusão Digital nas Comunidades - Telecentros \\
(Decreto 6 991, de 27 out. 2009) \\
41. Instituição do Regime Especial de Incentivos Tributários para a Indústria Aeronáutica Brasileira - RETAERO \\
(Medida Provisória 472, de 16 dez. 2009)
\end{tabular}

Fonte: Cano e Silva (2010); sem grifos no original.

cado na criação de mecanismos de rent seeking. Como vimos, as evidências dessa constatação estão embutidas na própria dinâmica e nos resultados do CNDI, onde $(i)$ predominaram soluções de compromisso, geralmente de temas de alcance mais horizontal como as políticas de apoio à inovação e (ii) mecanismos de gerenciamento do colegiado mais impessoais e objetivos, sob a condução/atuação de empreendedores políticos e de uma dominância ideacional relativamente coesa e homogênea em torno de conceitos e estratégias de uma política de apoio à indústria nacional. $\mathrm{O}$ papel dos empreendedores políticos foi fundamental para a construção dos consensos possíveis. Combinado com o domínio de novas agendas ideacionais sobre o desenvolvimento brasileiro - o "novo" ou "sócio" desenvolvimentismo -, as arenas geraram relações fecundas entre os atores participantes. Essa experiência, entretanto, não foi longeva o suficiente para institucionalizar e perenizar seus impactos positivos.

A dinâmica conselhista foi beneficiada por um contexto singular de crescimento econômico e relativa estabilidade política, o que contribuiu para limitar a replicabilidade dessa estratégia no segundo mandato de Lula (2007-2010), sobretudo depois da crise de 2008. Além disso, a fraca atuação de empreendedores e a próprio declínio do ideário desenvolvimentista no período seguinte de governo, retiraram energia das arenas de política industrial e do processo cooperativo, a despeito da existência formal do conselho e da própria política. A atuação desses atores não foi suficientemente transformadora para alterar os arranjos institucionais que continuaram dependentes de iniciativas individuais, esporádicas e imprevisíveis. Já com capacidade organizativa do CNDI ferida mortalmente, o modus operandi do que se chamou de "política industrial" posterior a 2008, na prática concreta, retornou lentamente ao leito original das práticas convencionais da micropolítica e da fragmentação endêmica, na perigosa fronteira das práticas clientelistas e paternalistas que sempre marcaram a história das políticas públicas brasileiras.

Jackson De Toni (jackson.detoni@abdi.com.br) é Doutor em Ciências Políticas pela Universidade de Brasília (UnB) e Gerente de Planejamento da Agência Brasileira de Desenvolvimento Industrial do Ministério do Desenvolvimento, Indústria e Comércio Exterior (MDIC). Afiliação Institucional: Ministério do Desenvolvimento, Indústria e Comércio Exterior, Brasília, DF, Brasil.

\section{Referências}

Abers, R. \& Keck, M., 2008. Representando a diversidade: estado, sociedade e "relações fecundas" nos conselhos gestores. Caderno CRH, (21)52, pp.99-112.

Alvarenga, G.; Pianto, D. \& Araújo, B., 2010. Impactos dos fundos setoriais nas empresas: novas perspectivas a partir da Função Dose-Resposta. Prêmio CNI Economia, Brasília. 
Barzelay, M. \& Cortazar-Velarde, J., 2004. Una guía práctica para la elaboración de estudios de caso sobre buenas prácticas en gerencia social. Washington, D.C.: BID/INDES.

Blyth, M., 2001. The Transformation of the Swedish Model: Economic Ideas, Distributional Conflict and Institutional Change. World Politics, 54, pp.1-26

Boschi, R. \& Gaitán, F., 2008. Capacidades estatais e estratégias de desenvolvimento na Argentina, no Brasil e no Chile. In W. Mancuso; M.A. Leopoldi \& W. Iglecias, eds. Estado, empresariado e desenvolvimento no Brasil: novas teorias, novas trajetórias. São Paulo: Editora de Cultura.

Bresser-Pereira, L., 2011. From Old to New Developmentalism in Latin America. In J. Ocampo \& J. Ross, eds. Handbook of Latin American Economics. London: Oxford University Press.

2007. Novo desenvolvimentismo e ortodoxia convencional. In E. Diniz, ed. Globalização, Estado e desenvolvimento: dilemas do Brasil no novo milênio. Rio de Janeiro: FGV.

Burt, R., 2004. Structural Holes and Good Ideas. The American Journal of Sociology, (110)2, pp.349-399.

CANO, W. \& SILVA, A.L.G., 2010. Política Industrial do Governo Lula. Texto para discussão, 182. Instituto de Economia, Unicamp.

Camp, J. \& Root, H., 1996. The Key to the Asian Miracle: Making shared Growth Credible. Washington, D.C.: Brookings Institution.

Costa, A.; Barros, D. \& Carvalho, J., 2011. A dimensão histórica dos discursos acerca do empreendedor e do empreendedorismo. Revista de Administração Contemporânea, (15)2, pp.179-197.

De Negri, F., 2012. Elementos para a análise da baixa inovatividade Brasileira e o papel das políticas públicas. Revista USP, 93, pp. $83-100$.

De Toni, J., 2013. Novos arranjos institucionais na política industrial do governo LULA: a força das novas ideias e dos empreendedores políticos. Tese de Doutorado. Brasília: Universidade de Brasília.

Donahue, J. \& Zeckhauser, R., 2006. Public-Private Collaboration. In M. Moran; M. Rein \& R. Goodin, eds. The Oxford Handbook of Public Policy. London: Oxford University Press.

Dudziak, E., 2007. "Lei de Inovação" e Pesquisa Acadêmica, o caso PEA. Tese de Doutorado. São Paulo: Universidade de São Paulo.

Evans, P., 2011. The Capability Enhancing Developmental State: Concepts and National Trajectories. Texto para Discussão, n. 63. CEDE.

Giesteira, L., 2010. O desenvolvimento após o desenvolvimentismo: origens, resultados e limitações da política brasileira de inovação tecnológica (1999-2008). Tese de Doutorado. Campinas: Unicamp.

Hall, P., 1989. The Political Power of Economic Ideas. Princeton: Princeton University Press. 2005. Preference Formation as a Political Process: The Case of Monetary Union in Europe. In I. Katznelson \& B. Weingast, eds. Preferences and Situations. New York: Russel Sage Foundation.

,2010. Historical Institutionalism in Rationalist and Sociological Perspective. In K. Thelen \& J. Mahoney, eds. Explaining Institutional Change. Cambridge, UK: Cambridge University Press.

Hall, P. \& Taylor, R., 1996. Political Science and the Three New Institutionalisms, Political Studies, 44(5), pp.936-957.

HAY, C., 2010. Ideas and the Construction of Interests. In D. Beland \& R. Cox, eds. Ideas and Politics in Social Science Research. Oxford: Oxford University Press.

Herzberg, B. \& Wright, A., 2005. Competitiveness Partnerships: Building and maintaining Public Private Dialogue to improve the Investment Climate. Working Paper S3683. World Bank.

Kannebley, S. \& Porto, G., 2012. Incentivos Fiscais à Pesquisa, Desenvolvimento e Inovação no Brasil: uma avaliação das políticas recentes. Brasília: Interamericano de Desenvolvimento.

Kingdon, J., 2011. Agendas, Alternatives and Public Policies. New York: Longman.

Lane, D. \& Maxfield, R., 1996. Strategy under Complexity: Fostering Generative Relationships. Long Range Planning, (29)2, pp.215-231.

Lindblom, C., 1959. The Science of Muddling Through. Public Administration Review, (19)2, pp.79-88.

Maxfield, S. \& Schneider, B.R., 1997. Business and the State in Developing Countries. Ithaca: Cornell University Press.

Nascimento, P. \& Oliveira, J., 2011. Redirecionamento, redistribuição, indução ou nenhuma das alternativas? Exame do papel das ações transversais no FNDCT entre 2004 e 2008. Texto para discussão, 1664. Brasília: IPEA.

Osborne, D. \& Gaebler, T., 1994. Reinventando o governo. Brasília: MH Comunicação.

Ostrom, E., 1990. Governing the Commons, the Evolution of Institutions for Collective Action. Cambridge, UK: Cambridge University Press.

2005. Understanding Institutional Diversity is Published. Princeton: Princeton University Press.

,2007. Challenges and Growth: the Development of the Interdisciplinary Field of Institutional Analysis. Journal of Institutional Economics, (3)3, pp.239-264.

Ostrom, E.; Gardner, R. \& Walker, J., 1994. Rules, Games, and Common Pool Resources. Ann Arbor: The University of Michigan Press.

Ragin, C., 1987. The Comparative Method: Moving beyond Qualitative and Quantitative Strategies. Los Angeles: University of California Press.

Rodrik, D., 2007. One Economics, many Recipes: Globalization, Institutions and Economic Growth. Princeton: Princeton University Press. 
Rua, M., 2005. Três hipóteses teóricas e uma situação empírica: a coordenação governamental na Rede de Proteção Social do governo do estado de Goiás. In X Congresso Internacional del Clad sobre la Reforma del Estado y de la Administración Pública. Santiago.

Sabel, C., 2004. Beyond Principal-Agent Governance: Experimentalist Organizations, Learning and Accountability. In E. Engelen \& M. Ho, eds. De Staat van de Democratie. Democratie voorbij de Staat. Amsterdam: Amsterdam University Press.

Say, J. B., 1983. Tratado de economia política. "Os economistas”. São Paulo: Abril Editora.

Schmidt, V., 2008. Discursive Institutionalism: The Explanatory Power of Ideas and Discourse. Annual Review of Political Science, 11 , pp.303-326.

Schneider, B.R., 2010. Business-Government Interaction in Policy Councils in Latin America: cheap talk, expensive changes or collaborative learning. IDB Working Papers Series, IDP-WP-167.

Schumpeter, J., 1982. A teoria do desenvolvimento econômico. "Os economistas". São Paulo: Abril Editora.

Sikkink, K., 1991. Ideas and Institutions: Developmentalism in Brazil and Argentina. Ithaca: Cornell University Press.

Tapia, J. \& Gomes, E., 2008. Ideias, interesses e mudanças institucionais. Tempo Social, (20)1, pp.239-264.

Thelen, K. \& Mahoney, J., eds. 2010. Explaining Institutional Change. Cambridge, UK: Cambridge University Press.

Tilly C.; McAdam, D. \& Tarrow, S., 2008. Methods for Measuring Mechanisms of Contention. Qualitative Sociology, (31)4, pp.307-331.

Velde, D.W., 2006. Measuring State-Business: Relations in Sub-Saharan Africa. IPPG Discussion Papers, n. 4.

Weingast, B. \& Katznelson, I., 2005. Intersections between Historical and Rational Choice Institutionalism. In , eds. Preferences and Situations. New York: Russel Sage Foundation.

\title{
Artigos em jornais
}

Souza, R.D.F.; Mol, P. \& Pacheco, C.A., 2009. Entrevista. Jornal da Unicamp, 23(429). Disponível em: http://www.unicamp.br/unicamp/unicamp_hoje/ju/maio2009/ju429_pag0607.php. Acesso em: 20 jul. 2015.

\section{Outras fontes}

CNDI/ABDI. S.d. Transcrições de atas e reuniões.

Finep. 2011. Relatório de gestão dos fundos setoriais. Rio de Janeiro: Finep/MCTI.

Finep. 2012. Relatório de Indicadores do Programa de Subvenção Econômica. Rio de Janeiro: APLA/Finep.

Ex-dirigente do MCT e da Finep. 2013. Entrevista concedida ao autor, 16 jul.

Furlan, Luis. 2012. Entrevista concedida ao autor, 5 out.

\begin{abstract}
The main objective of this paper is to identify variables that could explain the virtuous public-private relationship pattern on the production of public policies related to the industrial policy during the first Lula government round. The central argument of this research is that the National Industrial Development Council (CNDI), under the surveillance of the Ministry of Development, Industry and Foreign Trade (MDIC), has been acknowledged as a legitimized locus of the policy agenda building. Such processes resulted from two political factors: (i) the influence of neo-developmentalism ideas, especially those ones which influenced a new industrial policy, and (ii) the action of political entrepreneurs. The research was based on the analysis of the internal dynamics functionality of the National Council for Industrial Development (CNDI). The central question is if this collegiate worked as the real locus of political agenda. The available data were obtained through the assessment of the official registers, document analysis and interviews with the involved actors. One of the findings was that the established relationships and the formation of the policy agenda on the board contributed to the whole definition of the industrial policy in that period. The second finding was that the role of political entrepreneurs and neo-developmentalist ideologies contributed to facilitate such a dynamics. This article helps to understand the dynamics of tripartite forum of public policies in democratic context, its apparent causes, its positive results and its frustrations.
\end{abstract}

KEYWORDS: industrial policy; policy arenas; political entrepreneurs; neo-developmentalism; Lula government.

License information: This is an open-access article distributed under the terms of the Creative Commons Attribution License (CC-BY-NC 4.0), which permits unrestricted use, distribution, and reproduction in any medium, provided the original work is properly cited. 